\title{
SINTAGMAS NOMINAIS DESCONTÍNUOS
}

\author{
Roberto Gomes CAMACHO* \\ Nathalia Pereira de SOUZA-MARTINS ${ }^{* *}$
}

- RESUMO: O fenômeno sobre o qual este trabalho se debruça é o sintagma nominal (Np) que apresenta ordem não canônica de suas partes constituintes, denominado "descontínuo" por Keizer (2007). A análise e a descrição da descontinuidade têm por objetivo examinar, com base no arcabouço teórico da Gramática Discursivo-Funcional (HENGEVELD; MACKENZIE, 2008), que fatores pragmáticos, semânticos e formais motivam o falante a codificar ordenações específicas para esses Nps no Nível Morfossintático. O material de análise é constituído a partir de registros de língua falada retirados do banco de dados Iboruna, que representa a variedade falada no noroeste paulista, coletado pelo projeto ALIP, no interior do Grupo de Pesquisa em Gramática Funcional, na UNESP de São José do Rio Preto. Para os propósitos deste trabalho, exploram-se os seguintes critérios: (i) motivação para descontinuidade; (ii) tipo de material que intervém no Np; (iii) configuração morfossintática do Np descontínuo; e (iv) peso estrutural do elemento deslocado do $\mathrm{Np}$. A análise dos dados mostra que a descontinuidade é, predominantemente, motivada por aspectos pragmáticos, em especial, pela focalização de informações veiculadas por parte do SN. Além disso, o Np descontínuo prototípico é caracterizado pela interferência de material morfossintático entre o núcleo do sintagma e seus constituintes pós-nucleares. Embora haja esse distanciamento linear, a compreensão de enunciados descontínuos não é prejudicada em virtude de um vínculo semântico preservado no Nível Representacional, interpretação possível num modelo teórico como a GDF.

- PALAVRAS-CHAVE: sintagma nominal; descontinuidade; foco.

\section{Palavras iniciais}

A descontinuidade do sintagma nominal (doravante Np, para Noun Phrase) é um fenômeno morfossintático que rompe com a adjacência dos constituintes por apresentar uma ordenação não canônica, seja por interferência de elementos na morfossintaxe, como em (1a), seja por reposicionamento de modificadores, como em (1b):

\footnotetext{
Universidade Estadual Paulista (UNESP). Instituto de Biociências, Letras e Ciências Exatas. São José do Rio Preto SP - Brasil. roberto.camacho@unesp.br. ORCID: 0000-0002-8897-7953.

** Universidade Estadual Paulista (UNESP). Instituto de Biociências, Letras e Ciências Exatas. São José do Rio Preto SP - Brasil.nathaliapsouza12@gmail.com. ORCID: 0000-0003-0365-9591.
} 
(1) a. aí na parte de trás... dessa made(i)ra... da ou/ da o(u)tra made(i)ra [que eu tava falan(d)o] plana né?... (AC049; RP: L195)

b. no fundo tem mais dois cômodo que é:: ... um é o depósito [do meu pai] de doce... (AC027; DE: L.112)

$\mathrm{Na}$ literatura linguística, as discussões do fenômeno da descontinuidade, isto é, do deslocamento de um elemento constituinte do domínio do $\mathrm{Np}$, podem enquadrar-se em dois tipos: os que se concentram nas restrições morfossintáticas que se aplicam ao deslocamento e os que se dedicam mais à análise das circunstâncias que favorecem o deslocamento em situações em que o falante exerce uma escolha entre duas ordens de palavras aceitáveis. Este trabalho vincula-se ao segundo tipo, uma vez que se debruça sobre a codificação formal de Nps descontínuos com o intuito de verificar o que ativa uma ou outra forma de expressão.

Contemplando, portanto, a vocação funcional deste trabalho, nosso objetivo maior, além de descrever a natureza formal desse tipo de $\mathrm{Np}$, é investigar as motivações pragmáticas, semânticas e morfossintáticas que ativam a descontinuidade de suas partes constituintes.

Para Keizer (2007), que realizou um estudo de Nps descontínuos no inglês, é necessário levar em conta diferentes princípios de ordenação que determinariam a ordem final dos elementos e que estariam em interação e, em alguns contextos, em competição. No caso deste trabalho, dois princípios se mostram cruciais: o princípio de peso comunicativo ${ }^{1}$, segundo o qual estruturas com saliência pragmática, em especial, estruturas com estatuto de informação nova no discurso, se abrigariam na posição final da expressão linguística; e o de peso estrutural ${ }^{2}$, segundo o qual as estruturas seriam organizadas na morfossintaxe linear de acordo com sua complexidade crescente, isto é, da estrutura menos complexa para a mais complexa.

Este trabalho analisa a atuação desses dois princípios com a finalidade de constatar qual deles é predominantemente responsável pela descontinuidade em Nps e de fornecer explicações sobre a variação na ordem dos elementos, um tipo de análise já realizada por Camacho (2017) e por Souza-Martins (2020a, 2020b), que é a principal fonte dos dados em análise. A princípio, a hipótese principal deste trabalho, de conformidade com Keizer (2007), é a de que o princípio de peso comunicativo tem papel mais significativo na descontinuidade e define, com mais frequência, a ordem dos elementos, quando em competição com o princípio de peso estrutural.

Para tanto, assume-se, como perspectiva teórica, o arcabouço da Gramática Discursivo-Funcional (doravante GDF) (HENGEVELD; MACKENZIE, 2008), cujo principal objetivo é “dar conta dos fenômenos morfossintática e fonologicamente codificados nas línguas, seja como correlatos de aspectos pragmáticos e semânticos

\footnotetext{
A autora também se refere ao princípio como "princípio de foco-final". Neste trabalho, os termos serão empregados como sinônimos.

2 Também referido como "princípio de complexidade crescente" tanto no texto da autora como neste trabalho.
} 
da formulação, seja como portadores de propriedades inerentes da codificação" (HENGEVELD; MACKENZIE, 2012, p. 47).

É quase ocioso dizer que este estudo tem uma orientação funcionalista justamente por pressupor que determinadas codificações morfossintáticas são motivadas por aspectos pragmáticos e semânticos, o que implica numa investigação que vincule a análise das características morfossintáticas às motivações funcionais que subjazem à estrutura linguística. Nesse aspecto, a teoria discursivo-funcional mostra-se capaz de fornecer explicações linguísticas sobre o fenômeno analisado, o que justifica a escolha de tal abordagem.

É justamente dentro dessa orientação teórica que García Velasco (2010) e Van de Velde (2012) investigam alguns aspectos da descontinuidade em dados de língua inglesa e holandesa, respectivamente, propondo que o fenômeno corresponde a uma circunstância específica em que entidades relacionadas pragmática e semanticamente são codificadas separadamente no Nível Morfossintático, por conta de motivações advindas dos níveis mais altos de formulação. É, também, com base nesse postulado que nossas análises serão desenvolvidas, buscando verificar se, de fato, isso se aplica também aos dados do português, mais especificamente, da variedade falada na região de São José do Rio Preto.

Quanto à organização, este texto se estrutura da seguinte maneira: a seção 1 e suas subseções tratam do suporte teórico em que avulta uma perspectiva discursivo-funcional do Np e de sua descontinuidade; em seguida, a seção 2 identifica a proposta de trabalho e os procedimentos metodológicos; a seção 3 mostra as motivações funcionais que ativam o fenômeno da descontinuidade do Np; finalizando o trabalho, as Palavras Finais discutem as principais generalizações e implicações teóricas.

\section{Uma perspectiva funcional da descontinuidade}

\section{A gramática Discursivo-Funcional}

A Gramática Discursivo-Funcional toma como sua unidade básica de análise Atos Discursivos em vez de sentenças. É concebida como "o Componente Gramatical de um modelo global de interação verbal em que esse componente se liga ao Componente Conceitual, ao Componente de Saída e ao Componente Contextual" (HENGEVELD; MACKENZIE, 2012, p. 44), conforme mostra a arquitetura geral na Figura 1.

Esses três componentes não são gramaticais, mas interagem com o Componente Gramatical por meio das operações de formulação e de codificação; a primeira operação diz respeito a regras que regem as representações pragmáticas e semânticas, e a segunda diz respeito a regras que convertem tais representações em representações morfossintáticas e fonológicas.

O Componente Conceitual é considerado a força motriz do Componente Gramatical, pois ele desenvolve tanto a intenção comunicativa do falante quanto as 
conceptualizações referentes a fatores extralinguísticos. O Componente de Saída, baseando-se na informação que o Componente Gramatical fornece, gera as expressões, sejam elas escritas, acústicas ou de sinais. E, por fim, o Componente Contextual "contém a descrição do conteúdo e da forma do discurso precedente, do contexto real perceptível em que ocorre o evento de fala e das relações sociais entre os participantes" (HENGEVELD; MACKENZIE, 2012, p. 45).

Figura 1 - Layout geral da GDF

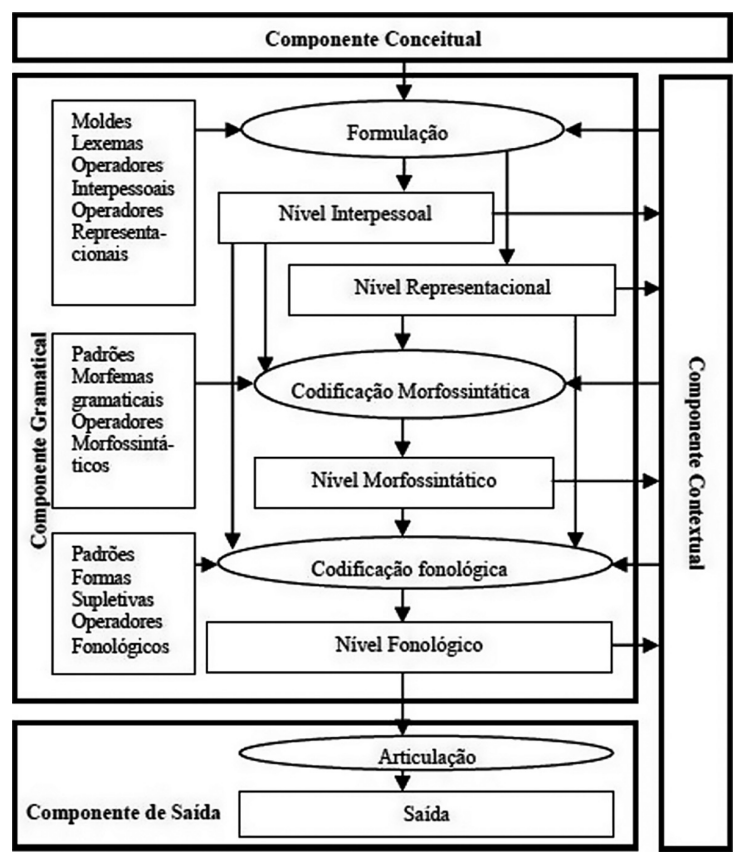

Fonte: Adaptado de Hengeveld e Mackenzie (2008, p.13).

Como mostra a Figura 1, a GDF se inicia com a intenção do falante e se desenvolve até a articulação, em virtude da suposição de que quanto mais a organização de um modelo de gramática se aproximar do processamento linguístico no indivíduo, mais eficaz ele será. A respeito disso, entende-se que a GDF "leva a abordagem funcional da linguagem ao seu extremo lógico” (HENGEVELD; MACKENZIE, 2012, p. 47), pois, dentro da organização descendente da gramática, a Pragmática rege a Semântica; a Pragmática e a Semântica regem a Morfossintaxe; e, finalmente, a Pragmática, a Semântica e a Morfossintaxe regem a Fonologia. ${ }^{3}$

Esse modo de organização não significa que os dois níveis de codificação sejam sempre determinados pelos dois níveis de formulação. Uma estrutura formal típica do inglês, como a forma representativa [there+be+Np], não tem nenhuma motivação propriamente pragmática e semântica. 
Dentro do Componente Gramatical, há quatro níveis de organização linguística, que, por sua vez, têm uma organização hierarquicamente ordenada em camadas. $\mathrm{O}$ primeiro deles é o Nível Interpessoal, responsável pelas ações linguísticas no processo de interação entre os participantes. Nele estão contidas as representações pragmáticas de formulação. Sua camada mais alta é o Movimento (M), que, por um lado, constitui a maior unidade de interação relevante para a análise linguística, e, por outro, pode conter um ou mais Atos Discursivos (A), a unidade básica do discurso. Por sua vez, cada Ato contém dois participantes da interação, Falante (S) e Destinatário (A) e um Conteúdo Comunicado $(\mathrm{C})$, que é a totalidade do que o falante deseja evocar na interação com o ouvinte. Cada Conteúdo Comunicado, por sua vez, contém um ou mais Subatos hierarquicamente subordinados ao Conteúdo Comunicado. Os Subatos podem ser de atribuição (T), evocando uma propriedade, ou de referência (R), evocando um referente.

O segundo nível é o Representacional, que trata dos aspectos semânticos de uma unidade linguística, sendo, por isso, responsável pela designação. Suas camadas se definem com base nas categorias semânticas que elas incluem. A mais alta é a do Conteúdo Proposicional (p), caracterizado como um construto mental, que contém um ou mais Episódios (ep), que, por seu turno, contém um ou mais Estados de Coisas (e), entidades de segunda ordem que podem ser localizadas no tempo e avaliadas em termos de sua realidade. A camada do Estado de Coisas pode ser organizada em Propriedade Configuracional (f) (predicado e seus argumentos), Indivíduo (x) (entidades de primeira ordem localizadas no espaço), Lugar (1), Tempo (t), Modo (m), Quantidade (q) e Razão (r).

O terceiro nível, o Morfossintático, dá conta dos aspectos estruturais de uma unidade linguística. Além de ser, muitas vezes, funcionalmente motivado, esse nível tem seus próprios princípios de organização, o que interessa a este trabalho. Além disso, ele recebe o input dos níveis de formulação e é responsável pela codificação morfossintática das representações interpessoais e representacionais. Sua camada mais alta é a Expressão linguística (Le), qualquer conjunto de, pelo menos, uma unidade morfossintática, que, por sua vez, pode ser formado por Orações $(\mathrm{Cl})$, Sintagmas $(\mathrm{P})$ e Palavras (W).

O quarto e último nível é o Fonológico, que trata de todos os aspectos da codificação não abrangidos pelo nível morfossintático. É ele que recebe o input dos três outros níveis e fornece o input para o Componente de Saída. Suas camadas são: o Enunciado, o maior segmento de discurso abrangido pelo nível fonológico, a Frase Entonacional, a Frase Fonológica, a Palavra Fonológica, a Sílaba e o Pé.

Interessam-nos, aqui, principalmente, as relações entre os níveis mais altos de formulação - o Interpessoal e o Representacional - e o Morfossintático, uma vez que lidar com o fenômeno da descontinuidade requer tratar da ordem de palavras no Nível Morfossintático e das motivações advindas dos níveis mais altos. Na próxima seção, objetiva-se discutir como a GDF concebe o Np. 


\section{Um enfoque discursivo-funcional do $\mathrm{Np}$}

Do ponto de vista puramente formal, o Np é um conjunto de elementos dentro da oração que tem como núcleo um substantivo. Segundo Perini (1995), pode-se definir o Np de maneira muito simples, entendendo-o como "o sintagma que pode ser sujeito de alguma oração" (PERINI, 1995, p. 92), como se vê em (2-3).

(2) Esse professor é um neurótico. (PERINI, 1995, p. 92)

(3) Um neurótico rabiscou meus livros. (PERINI, 1995, p. 92)

Com base nesses exemplos, o autor considera que esse professor (2) é um Np porque é sujeito da primeira oração, e um neurótico também o é em (3), embora apareça em (2) na posição de predicado, exercendo uma função não referencial, mas atributiva. Para além da definição formal de Perini (1995), pode-se postular que, do ponto de vista semântico, além de denominar, o substantivo se refere às coisas do mundo, isto é, a uma entidade do mundo extralinguístico, real ou imaginário. É a função que exercem esse professor em (2) e um neurótico em (3), definição que, todavia, excluiria este mesmo Np em (2) na função semântica de predicado.

Com base nessa diferença, passemos, a seguir, a olhar o $\mathrm{Np}$ de uma perspectiva pragmática e semântica, o que implica a necessidade de um tratamento mais complexo para a definição da categoria, e a assumir que, do ponto de vista pragmático, um $\mathrm{Np}$ pode exercer a função de um Subato Referencial, como esse professor em (2) e um neurótico em (3), e também a função de um Subato Atributivo, que é a de um neurótico em (2).

A função atributiva e a referencial que os Nps exercem no Nível Interpessoal são tratadas como Subatos, o Atributivo e o Referencial, ${ }^{4}$ os quais, no Nível Representacional, correspondem, respectivamente, à evocação das funções semânticas de predicação e de designação. A organização em níveis e camadas do modelo da GDF, vistas na seção anterior, parece dar uma solução teórica satisfatória para as características pragmáticas, semânticas e morfossintáticas do Np. Para mostrar a interação entre os níveis, fornecemos, na Figura 2, a proposta de formalização de Hengeveld (2008) para análise do caso padrão de Np, no inglês the intelligent girl.

\footnotetext{
4 Um Subato Referencial é uma tentativa de evocar um referente e um Subato Atributivo é uma tentativa de evocar uma propriedade, cf. Hengeveld e Mackenzie (2008).
} 
Figura 2 - Representação do Np prototípico

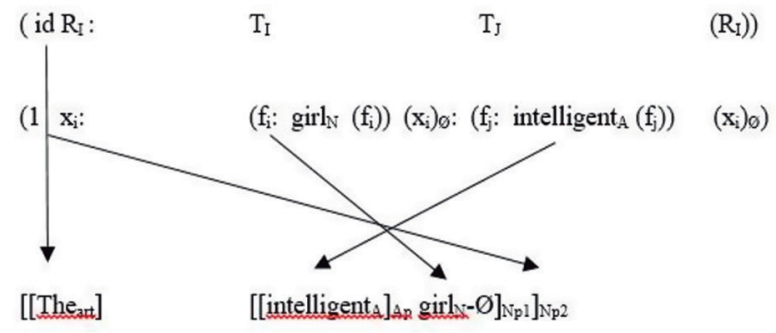

Fonte: Hengeveld (2008, p. 46).

A tríplice representação na Figura 2 mostra, na realidade, que é justamente o estatuto referencial do $\mathrm{Np}$ no Nível Interpessoal (IL: Interpersonal Level) que identifica seu uso prototípico, embora, como mostra o exemplo (3), um Np possa, secundariamente, evocar um Subato Atributivo.

Esse estatuto pragmático do $\mathrm{Np}$ prototípico é representado por $\mathrm{R}_{\mathrm{I}}$ no Nível Interpessoal, que traduz o Subato Referencial; este contém, por sua vez, duas instanciações de um Subato Atributivo $\left(\mathrm{T}_{\mathrm{I}}\right.$ e $\left.\mathrm{T}_{\mathrm{J}}\right)$, implicando que a denotação do Np no Nível Representacional (RL: Representational Level) envolve duas propriedades lexicais $\left(f_{i}\right.$ e $f_{j}$ ) correspondentes. Ainda nesse nível, $\left(\mathrm{x}_{\mathrm{i}}\right)$ indica que o Np denota uma entidade de primeira ordem, no caso girl, modificada por intelligent que têm as propriedades $f_{i}$ e $f_{j}$, respectivamente, para representar o fato de que a denotação referencial do $\mathrm{Np}$ tem uma expressão lexical no Nível Representacional.

É também nesse nível que se indica a natureza nominal do Np, marcada na Figura 2, como a categoria $\mathrm{N}$ de nome, subscrita no item lexical atuando como núcleo, e como a categoria A de adjetivo, subscrita no item lexical atuando como modificador. Com base na informação fornecida nos níveis mais altos, o codificador produz formalmente um Np no Nível Morfossintático (ML: Morphosyntactic Level) com a ordenação típica do inglês, em que o adjetivo na função de modificador precede o nome na função de núcleo; no caso da variedade do português examinada, se daria a situação inversa. É, portanto, no Nível Morfossintático que se dá a ordenação dos constituintes.

Como se vê, o Sintagma Nominal (Np) é uma categoria morfossintática que evoca, como membro prototípico, ${ }^{5}$ um Subato Referencial no Nível Interpessoal e denota, no Nível Representacional, um Indivíduo (x), que é, nesse caso, uma entidade de primeira ordem, que pode ser localizada no espaço e ser avaliada em termos de sua existência.

Hengeveld (2008) identifica outros tipos de Np que identificam membros menos prototípicos da categoria. São os casos de Nps não nominais ( Vi o que você fez); de Nps que denotam entidades de ordem superior, como estados de coisas (a produção de leite) e proposições (a crença na mudança); de Nps com nomes próprios e pronomes (Pedro saiu/ele saiu), que são desprovidos de denotação no Nível Representacional; de Nps que representam vocativos (Ei, menina!); de Nps com x incorporado em línguas que os contêm e, finalmente, de Nps atributivos, como um neurótico de (3). 
Ele é formalmente constituído pelo artigo definido (Art), que representa, no Nível Morfossintático, o caráter identificável do referente no Nível Interpessoal, e o $\mathrm{Np}_{2}$, que é, por sua vez, formado pelo $\mathrm{Np}_{1}$, constituído por um nome $(\mathrm{N})$, exercendo o papel de núcleo, e por um Sintagma Adjetival (Adjp), que é, no exemplo, representado pelo adjetivo (A) intelligent.

Vê-se que a complexidade funcional do $\mathrm{Np}$ tem suporte num modelo de gramática, como a GDF, justamente por representar, em níveis e camadas hierarquicamente organizadas, esse modo de funcionamento que projeta uma perspectiva pragmática, semântica e morfossintática para uma unidade que, de resto, é tratada apenas como categoria puramente sintática. A próxima seção mostrará como esse modelo é capaz de identificar também alguns princípios de ordenação que permitam explicar, da perspectiva funcionalista, a descontinuidade e, mais especificamente, o Np descontínuo.

\section{Ordenação de constituintes e descontinuidade}

O Np descontínuo pode ser entendido como uma escolha não consciente do falante entre duas ordens de palavras formalmente aceitáveis de organização morfossintática. Conforme veremos mais adiante, todavia, há casos em que a ordem parece ser uma estratégia deliberada do falante para produzir determinados efeitos na situação discursiva. De qualquer modo, a relação entre o nível morfossintático e os dois níveis mais altos que lhe servem de input é governada por três princípios, os de iconicidade, de integridade de domínio e de estabilidade funcional. Cada um desses princípios contribui, a seu modo, para maximizar o paralelismo entre as estruturas, reforçando a transparência e a facilidade de interpretação.

Comecemos pelo princípio de iconicidade. Ainda que a linguagem seja um constructo simbólico que, como tal, é capaz de tolerar uma relação maximamente arbitrária entre forma e conteúdo, as línguas naturais dispõem de uma diversidade de fenômenos que propiciam certo grau de homologia entre essas duas dimensões. São esses os fenômenos abarcados pelo princípio de iconicidade, cuja atuação pode ser ilustrada pela correspondência entre a ordem em que se introduzem as categorias do Nível Interpessoal e do Nível Representacional e a ordem em que essas categorias são expressas na codificação formal, como se vê em (4a-b).

(4) a. O jogo começou às 16:00 e terminou empatado.

b. O jogo, que começou às 16:00, terminou empatado.

(adaptado de Hengeveld e Mackenzie, 2008, p. 284)

O exemplo (4a) ilustra o caso de um movimento (move) com dois atos discursivos, cuja ordenação morfossintática conserva a sequência cronológica dos eventos evocados e designados, no Nível Representacional, como dois Estados de Coisas. De conformidade 
com essa ordem, o Nível Morfossintático codifica essa relação sob a forma de uma expressão linguística consistindo em duas orações coordenadas.

Seria possível evitar a relação icônica, se o interesse funcional do falante fosse dar maior proeminência à informação de que o jogo terminou empatado do que ao momento de início, como aparece em (4b). Nesse caso, o movimento consistiria em dois atos discursivos, um dos quais, o subsidiário, aparece como oração adjetiva no nível morfossintático e o nuclear, como a oração principal, dando abertura a três frases entonacionais no Nível Fonológico. A formulação de um dos dois enunciados consiste numa escolha consciente do falante, que emprega a estratégia de relativização para tornar um ato discursivo mais proeminente que o outro. Tudo é, como se vê, uma questão de intenção comunicativa que dá total primazia ao falante na situação de interação, sempre levando em conta seu interlocutor. ${ }^{6}$

Outro princípio que restringe o Nível Morfossintático por refletir a organização dos níveis que lhe servem de input é o de integridade de domínio. Esse princípio se refere a uma preferência universal para que as unidades que, juntas pertencem aos níveis Interpessoal e ao Representacional, sejam também justapostas umas às outras no Nível Morfossintático (HENGEVELD; MACKENZIE, 2008). Em outras palavras, modificadores deveriam abrigar-se idealmente na expressão morfossintática em posição adjacente aos núcleos que escopam; similarmente, funções e operadores deveriam ser realizados por elementos próximos das unidades a que se aplicam.

A violação do princípio de integridade de domínio, que provoca o aparecimento de descontinuidades, constitui um tipo de violação da relação de transparência, que consiste numa relação biunívoca entre as unidades de significado e as unidades formais, conforme entendida por Hengeveld e Mackenzie (2008) e, em particular, Hengeveld (2011) e Leufkens (2015).

Por transparência deve-se entender esse alinhamento idealmente biunívoco entre a estrutura hierárquica dos níveis mais altos entre si mesmos e entre a estrutura hierárquica deles e a do Nível Morfossintático; nesse caso, a evocação de um Subato de referência, por exemplo, não deveria ser interrompida pela evocação de outro Subato de referência, como ocorre em (4b), ou por algum Subato de atribuição. Esse princípio se aplica por default, ou seja, caso tudo o mais seja igual, a correspondência entre os níveis garantiria respeito ao princípio de integridade de domínio.

\footnotetext{
De conformidade com Neves (2012), defende-se aqui a existência de um sistema gramatical único para as modalidades falada e escrita da linguagem, mas que contemple também as especificidades de uso de cada qual. A autora lembra o difícil limite de distinção, do ponto de vista das estruturas básicas, entre a língua falada e a língua escrita, questão que ela conduz para os diversos compartimentos (ou níveis) da "gramática", observando, por exemplo, que, em alguns campos, não no todo de uma maneira geral, "as diferenças se discutem mais fortemente no terreno da interação (modo de produção, condições de uso, interesses e propósitos específicos), enquanto em outros campos as diferenças já se discutem mais especificamente no nível do sistema" (NEVES, 2012, p. 78). Ressalte-se, todavia, que em nenhum dos casos, desaparece algum dos componentes (sintático, semântico ou pragmático) que se integram para compor a gramática da língua.
} 
O terceiro princípio, que interessa discutir aqui, o de estabilidade funcional, requer que constituintes com a mesma especificação, quer interpessoal quer representacional, sejam colocados numa mesma posição fixa em relação a outras categorias. ${ }^{7}$

Outras circunstâncias, além da atuação desses três princípios, que ativam a descontinuidade, são evocados por Keizer (2007) como o princípio de peso-final (ou complexidade estrutural) e o de foco-final (ou peso comunicativo) para contemplar as circunstâncias pragmáticas.

O primeiro princípio diz respeito ao fato de a ordem livre de palavras ser ativada por um processamento sintático, determinada pela tendência de otimização das estruturas da língua, ou seja, a estrutura menos complexa disponível (HAWKINS, 1983). Dik (1997) se refere a essa restrição como Princípio de Complexidade Crescente (Principle of Increasing Complexity), entendendo-o como uma preferência para ordenar os constituintes de uma expressão linguística em termos do grau progressivamente mais elevado de complexidade de seus constituintes.

É natural, segundo Dik (1997), que esse princípio se contraponha ao de estabilidade funcional: embora os constituintes com o mesmo perfil funcional se abriguem na mesma posição, essa preferência pode ser superada pela diferença de complexidade interna entre eles. A complexidade é, nesse mesmo sentido, referida como "peso" por Mallinson e Blake (1981) e Hawkins (1983). Trata-se, assim, de motivações em competição nos termos de Du Bois (1985).

Sobre o segundo princípio, o de foco-final (ou peso comunicativo), de acordo com Keizer (2007) e Dik (1997), têm-se empregado diferentes noções funcionais, discursivas ou cognitivas para explicar a maneira como se ordenam os elementos da oração. Segundo o Princípio de Saliência Pragmática (Principle of Pragmatic Highlighting), constituintes com uma função pragmática especial são colocados preferentemente em "posições especiais", incluindo, pelo menos, a posição de início de oração.

De conformidade com esse princípio, Hengeveld e Mackenzie (2008) postulam três posições disponíveis no Nível Morfossintático para a inserção de elementos na oração: a posição inicial $\left(\mathrm{P}^{\mathrm{I}}\right)$, a posição medial $\left(\mathrm{P}^{\mathrm{M}}\right)$ e a posição final $\left(\mathrm{P}^{\mathrm{F}}\right)$ de acordo com os postulados de Dik (1997). Hengeveld e Mackenzie (2008), todavia, acrescentam posições relativas para cada uma dessas posições absolutas, como $\mathrm{P}^{\mathrm{I}+\mathrm{n}}, \mathrm{P}^{\mathrm{M}+/-\mathrm{n}}$ e $\mathrm{P}^{\mathrm{F}-\mathrm{n}}$, que se tornam disponíveis apenas quando as posições absolutas $\left(\mathrm{P}^{\mathrm{I}}, \mathrm{P}^{\mathrm{M}}\right.$ e $\left.\mathrm{P}^{\mathrm{F}}\right)$ estiverem preenchidas, como pode ser observado no Quadro 1.

Quadro 1 - Posições absolutas e relativas da oração.

\begin{tabular}{|l|l|l|l|l|l|l|l|l|l|l|l|l|}
\hline $\mathbf{P}^{\mathrm{I}}$ & $\mathrm{P}^{\mathrm{I}+1}$ & $\mathrm{P}^{\mathrm{I}+\mathrm{n}}$ & $\mathbf{P}^{2}$ & $\mathrm{P}^{2+\mathrm{n}}$ & $\mathrm{P}^{\mathrm{M}-\mathrm{n}}$ & $\mathrm{P}^{\mathrm{M}-1}$ & $\mathbf{P}^{\mathbf{M}}$ & $\mathrm{P}^{\mathrm{M}+1}$ & $\mathrm{P}^{\mathrm{M}+\mathrm{n}}$ & $\mathrm{P}^{\mathrm{F}-\mathrm{n}}$ & $\mathrm{P}^{\mathrm{F}-1}$ & $\mathbf{P}^{\mathrm{F}}$ \\
\hline
\end{tabular}

Fonte: Pezatti (2014, p. 82).

Em certas línguas, a disposição de constituintes exercendo função focal é determinada por sua posição em relação ao verbo. O turco, por exemplo, insere o constituinte com função de Foco na posição imediatamente pré-verbal, e fixa a posição de tempo no verbo na posição final da oração. 
Entende Dik (1997) que as duas posições periféricas ( $\mathrm{P}^{\mathrm{I}}$ e $\left.\mathrm{P}^{\mathrm{F}}\right)$ são psicologicamente salientes e extremamente relevantes para o processo de comunicação, enquanto a medial $\left(\mathrm{P}^{\mathrm{M}}\right)$ é não somente a posição menos saliente, mas também, estruturalmente, não deve ser considerada uma posição única em função do número variável de constituintes que uma oração pode conter.

Com base no Princípio de Saliência Pragmática, abrigam-se constituintes com função pragmática especial preferencialmente em "posições especiais", incluindo, pelo menos, a posição inicial da oração, ou $\mathrm{P}^{\mathrm{I}}$. Esse princípio explicaria o deslocamento de elementos tanto para o início da oração (5a) como para o final (5b), demonstrando a intenção do falante de realçar uma informação de seu discurso de modo a alojá-la numa posição específica.

(5) a. Doutores sempre houve muito poucos. (PEZATTI, 2014, p. 98)

b. Um anúncio foi feito de que ele estava indo para o Departamento de Educação e Ciência. (KEIZER, 2007, p. 288, exemplo adaptado)

Sentenças como (5a) mostram como elementos que contêm informação dada são deslocados para fora de seu domínio e realocados no início da oração, posição típica de Tópico na língua portuguesa; já orações como (5b) ilustram o que Keizer (2007) chama de peso comunicativo: a informação focal contida em parte do Np é deslocada para a posição final da oração, apropriada para a inserção de informações novas. $\mathrm{O}$ fenômeno também é mencionado como “extraposição" pela autora, embora esse seja um termo já usado por pesquisadores de outras abordagens teóricas, especialmente a gerativa.

No entanto, como previsto por Dik (1997), por Keizer (2007) e também por Du Bois (1985), em determinados contextos, os princípios podem entrar em competição: cada um favorece uma ordem específica, o que pode requerer do falante a execução de um ato de equilíbrio compensatório mediante a seleção da forma de expressão que melhor atenda aos propósitos comunicativos. ${ }^{8}$

Nos dois modelos funcionalistas holandeses, a Teoria da Gramática Funcional (DIK, 1997) e a Gramática Discursivo-Funcional (HENGEVELD; MACKENZIE, 2008), é, como vimos, o Nível Interpessoal que fornece os moldes para o falante formular suas mensagens com base em suas estimativas do estado mental do ouvinte, moldes esses motivados por funções pragmáticas. Pezatti (2014) destaca três delas, reconhecidas

\footnotetext{
Corre-se claramente o risco aqui de admitir uma posição funcionalista que Du Bois (1985) denomina "funcionalismo transparente". Segundo essa perspectiva teórica, fatores sintáticos aparentemente autônomos constituem, na realidade, o resultado transparente dos objetivos funcionais do falante, de modo que se torna desnecessário postular algum mecanismo sintático arbitrário para a descrição da língua. Em outros termos: as únicas forças que governam a "sintaxe" são as forças positivas da linguística externa, como mecanismos de processamento de base biológica, intenções comunicativas etc. (DU BOIS, 1985). Não é essa a posição que se assume aqui: reconhece-se o princípio de que algumas regras de organização morfossintática são formalmente motivadas sem qualquer influência das intenções comunicativas do falante, que estariam afeitas a princípios pragmáticos regendo a organização formal.
} 
pela GDF, que têm impacto sobre a expressão formal: tópico, foco e contraste, ${ }^{9}$ mas acrescenta uma quarta, a de ênfase. Vamos nos deter aqui apenas na função Foco em razão de sua relevância para os propósitos deste texto.

A função Foco consiste na seleção estratégica do falante de uma informação nova com o propósito de preencher uma lacuna na informação potencial do ouvinte ou corrigir uma informação de que ele já disponha. Pode-se atribuir uma informação focal ao Subato referencial, ao Subato atributivo ou à oração como um todo, no caso de afirmações téticas (Chegou o correio) em que todos os elementos constituintes são novos.

O Princípio de Saliência Pragmática provoca uma organização descontínua do Np no Nível Morfossintático, que rompe com a ordenação linear de seus constituintes. Entende García Velasco (2010) que o termo descontinuidade, de modo geral, refere-se a uma unidade linguística cujos membros são interrompidos por material linguístico interferente na morfossintaxe linear. Esse conceito, segundo ele, se distingue da noção de deslocamento, ${ }^{10}$ que, por sua vez, diz respeito à unidade linguística que, em determinado contexto sintático, aparece em uma posição diferente da que apareceria se estivesse de acordo com a ordem canônica de palavras requerida pela gramática da língua.

A diferença entre as duas noções, ainda para o autor, é que deslocamento é definido com base nas categorias sintáticas da língua, sendo, assim, uma noção teoricamente independente; já descontinuidade é um termo que depende do modo como cada modelo teórico concebe a noção de constituinte. Em vista disso, é evidente a necessidade de deixar claro o que é considerado descontinuidade à luz da GDF.

Traçando um percurso entre diferentes perspectivas da descontinuidade a fim de definir em qual delas se enquadra a GDF, García Velasco (2010) cita Huck e Ojeda (1987 apud GARCÍA VELASCO, 2010), os quais explicitam três abordagens para o fenômeno na teoria linguística: interpretação semântica constante, dependência sintática e unidade semântica.

A primeira delas considera que um constituinte é uma sequência fonética com a mesma contribuição semântica, não importa se seus membros apareçam ou não contíguos. A segunda define constituinte com base em relações de dominância típicas de uma configuração arbórea à qual se possam subsequentemente aplicar transformações por movimento, de modo a produzir, assim, vários níveis de análise sintática. A terceira delas postula que elementos sintáticos não adjacentes não podem formar um constituinte, embora possam ser projetados numa representação semântica em que o valor deles possam formar uma unidade (HUCK; OJEDA, 1987 apud GARCÍA VELASCO, 2010).

9 Essas categorias diferem das que Dik (1997) inicialmente postulava, uma vez que, por exemplo, foco contrastivo é agora uma função pragmática própria, denominada "contraste".

10 O termo deslocamento (displacement em inglês, no texto original) não deve ser associado a transformações ou movimentos da estrutura linguística, como concebe a teoria gerativista. Neste texto, usa-se o termo para indicar que uma estrutura linguística assume um posicionamento não prototípico, por conta de motivações específicas do falante. Isso não quer dizer que o constituinte se tenha movido de sua posição original, mas que tenha sido alojado numa posição em que não estaria se não fosse pela intenção comunicativa do falante. 
Para García Velasco (2010), é nessa terceira abordagem que se enquadra a GDF, já que esse modelo teórico permite que unidades separadas morfossintaticamente tenham uma conexão semântica no Nível Representacional.

Outro autor, Van de Velde (2012), argumenta na mesma direção de García Velasco (2010), na análise que faz de sintagmas preposicionais (doravante Pps) que são deslocados para a posição inicial da oração, fenômeno conhecido por "extração". Em consonância com García Velasco (2010), Van de Velde (2012) defende que, numa oração como "Sobre Amsterdã, eu li dois livros", o Np [dois livros] e o Pp [sobre Amsterdã] não formam um único constituinte no Nível Morfossintático, tendo eles, no entanto, uma conexão no Nível Representacional, no qual se estabelecem as relações semânticas entre núcleo e modificador, como se observa na representação a seguir.

(6) Sobre Amsterdã, eu li dois livros.

NR: $\left(\mathrm{p}_{\mathrm{i}}:\left(\operatorname{Past~}_{\mathrm{i}}:\left[\left(\mathrm{f}_{\mathrm{i}}: \operatorname{ler}\left(\mathrm{f}_{\mathrm{i}}\right)\right)\left(\mathrm{x}_{\mathrm{i}}\right)_{\mathrm{A}}\left(2 \mathrm{x}_{\mathrm{j}}:\left[\left(\mathrm{f}_{\mathrm{j}}: \operatorname{livro}\left(\mathrm{f}_{\mathrm{j}}\right)\right)\left(\mathrm{x}_{\mathrm{j}}\right)\right]:\left[\left(\mathrm{f}_{\mathrm{k}}:\left[\left(\mathrm{f}_{\mathrm{l}}:\right.\right.\right.\right.\right.\right.\right.\right.$ sobre $\left.\left(\mathrm{f}_{\mathrm{f}}\right)\right)$ $\left.\left.\left.\left.\left.\left.\left(\mathrm{l}_{\mathrm{i}}\right)\right]\left(\mathrm{f}_{\mathrm{k}}\right)\right)\left(\mathrm{x}_{\mathrm{j}}\right)\right]\right)_{\mathrm{U}}\left(\mathrm{e}_{\mathrm{i}}\right)\right)\left(\mathrm{p}_{\mathrm{i}}\right)\right)^{11}$

NM: (Le $:\left(\mathrm{Cl}_{\mathrm{i}}\right.$ : $\left[\left(\mathrm{Pp}_{\mathrm{i}}\right.\right.$ :-sobre Amsterdã - $\left.\left(\mathrm{Pp}_{\mathrm{i}}\right)\right)\left(\mathrm{Np}_{\mathrm{i}}\right.$ : -eu- $\left.\left(\mathrm{Np}_{\mathrm{i}}\right)\right)\left(\mathrm{Vp}_{\mathrm{i}}\right.$ :-li- $\left.\left.\left(\mathrm{Vp}_{\mathrm{i}}\right)\right)\right]$ $\left(\mathrm{Np}_{\mathrm{j}}\right.$ : -dois livros- $\left.\left.\left.\left(\mathrm{Np}_{\mathrm{j}}\right)\right)\left(\mathrm{Cl}_{\mathrm{i}}\right)\right)\left(\mathrm{Le}_{\mathrm{i}}\right)\right)$

(Adaptado de Van de Velde, 2012, p. 9)

Além disso, essa organização morfossintática, para ele, é resultado de uma motivação derivada do Nível Interpessoal, uma vez que o Pp exerce função tópica, estratégia pragmática que motivaria a escolha de deslocá-lo para a posição inicial da oração. A representação da sentença em holandês Van de eerste klasse wordt alleen de beste ploeg geselecteerd (em português: da premier league, somente o melhor time é selecionado) contida em (7) demonstra como a GDF acomoda o fenômeno no Nível Interpessoal.

(7) Van de eerste klasse wordt alleen de beste ploeg geselecteerd NI: (MI: (AI: CI: [+ id (RI)Topic (TI) +id (RJ): alleen(RJ)] (CI)) (AI)) (MI))

NR: (pi: (ei: [(fi: selecteer (fi)) (1 xi: [(fj: ploeg (fj)) (xi)]: [(fk: best (fk)) (xi)]: [(fl: [(fm: van (fm)) (xj: -eerste klasse- (xj))] (fl)])U] (ei)) (pi))

NM: $\left(\operatorname{Le}_{\mathrm{i}}\right.$ : $\left(\mathrm{Cl}_{\mathrm{i}}\right.$ : $\left[\left(\mathrm{Pp}_{\mathrm{i}}\right.\right.$ : -van de eerste klasse- $\left.\left(\mathrm{Pp}_{\mathrm{i}}\right)\right)\left(\mathrm{Vw}_{\mathrm{i}}:\right.$ wordt $\left.\left(\mathrm{Vw}_{\mathrm{i}}\right)\right)\left(\mathrm{Np}_{\mathrm{i}}\right.$ : -alleen de beste ploeg- $\left.\left(\mathrm{Np}_{\mathrm{i}}\right)\right)\left(\mathrm{Vp}_{\mathrm{i}}\right.$ : -geselecteerd- $\left.\left.\left.\left.\left.\left(\mathrm{Vp}_{\mathrm{i}}\right)\right)\right]\left(\mathrm{Cl}_{\mathrm{i}}\right)\right) \mathrm{Le}_{\mathrm{i}}\right)\right)$

(VAN DE VELDE, 2012, p. 10)

É a posição de García Velasco (2010), combinada com a de Van de Velde (2012), que se defende neste trabalho.

${ }_{11} \mathrm{X}_{\mathrm{i}}$ refere-se a "eu" e $1_{\mathrm{i}}$ refere-se a "Amsterdã", conforme Van de Velde (2012). 


\section{Proposta de trabalho e procedimentos metodológicos}

Ainda que as considerações de Pezatti (2014) se apliquem ao nível oracional, as funções pragmáticas, motivadoras de ordens alternativas, são relevantes também para o exame das motivações da descontinuidade do $\mathrm{Np}$, como parte de uma teoria multifuncional. Com efeito, Keizer (2007) considera que a única maneira profícua de explicar a complexidade da variação potencial é assumir que a ordem dos constituintes do Np é determinada por princípios e preferências em interação e possivelmente em competição.

Pela perspectiva funcional, de acordo com Dik (1997) e Keizer (2007), é necessário postular, para isso, uma teoria multifuncional de ordenação de constituintes, baseada nas seguintes suposições:

(i) os padrões de ordenação encontrados em uma língua resultam de princípios em interação;

(ii) cada um desses princípios é em si mesmo funcionalmente motivado;

(iii) dois princípios em interação nem sempre definem a mesma preferência de ordenação;

(iv) como a solução para a ordenação numa dada língua contém um elemento de conciliação, ela acaba se caracterizando por um certo grau de tensão.

Keizer (2007) postula a hipótese de que a decisão do falante de alojar para fora do $\mathrm{Np}$ material pertencente a sua estrutura é determinada por princípios independentes. Quando dois ou mais princípios definem ordens conflitantes, é possível que o falante execute uma espécie de ato de equilíbrio compensatório, cujo resultado depende de um dado contexto discursivo (intenções do falante, identidade do ouvinte etc.).

$\mathrm{O}$ ato de equilíbrio compensatório parte de duas premissas: o emprego da forma menos complexa e a eficiência atingida mediante indicação do status pragmático em termos das funções que exercem os elementos envolvidos - constituinte principal, material de intervenção e constituinte deslocado - para atingir o efeito comunicativo previsto. $\mathrm{O}$ ato de equilíbrio tem, portanto, duas funções:

(i) tornar o enunciado menos complexo, o que implica reduzir a dificuldade de processamento cognitivo por dispor o material mais complexo na posição final de uma construção;

(ii) salientar o material em foco geralmente apresentado como novo no discurso. Todavia, outras funções pragmáticas, além de Foco, podem atuar como motivações da descontinuidade.

O resultado desse ato de equilíbrio pode conduzir a um enunciado que, do ponto de vista do falante, é o melhor que ele pode produzir para criar o efeito desejado. Do ponto de vista do ouvinte, uma abordagem multifuncional parece perfeitamente 
plausível, pois ele opta por uma interpretação que, no contexto dado, está de acordo com a escolha de construção do emissor (KEIZER, 2007).

Com base nessa teoria multifuncional, Keizer (2007) postula as seguintes hipóteses para a descontinuidade do Np:

(i) a opção do falante por abrigar material estruturalmente pertencente ao $\mathrm{Np}$ para fora de seus limites é determinada por dois princípios independentes: peso estrutural e peso comunicativo; (ii) na maioria dos casos, esses dois fatores favorecem a mesma ordem; (iii) quando os dois fatores favorecerem ordens em competição, cabe ao falante decidir qual dos dois fatores, dadas as circunstâncias discursivas, sobrepuja o outro em termos de eficiência; (iv) outros fatores independentes podem também exercer um papel relevante; embora não tenham força suficiente para determinar a ordenação por si mesmos, podem constituir o fiel da balança em caso de "empate"; (v) o falante acredita que a ordem final dos elementos, nas circunstâncias discursivas, é a mais eficiente entre as disponíveis, apesar de ter sido violado pelo menos um dos princípios cruciais de ordenação. (KEIZER, 2007, p. 273-274, tradução nossa). ${ }^{12}$

Com base nessas premissas, a hipótese central deste trabalho prevê a atuação dos princípios de peso estrutural e de peso comunicativo e a prevalência deste em uma possível competição entre eles em circunstâncias discursivas que favorecem a aparição de descontinuidades. Isso implica pressupor a primazia de motivações pragmáticas sobre as morfossintáticas, hipótese que se alinha à organização hierárquica do modelo teórico da GDF.

O material de análise é constituído por uma amostra representativa da modalidade falada, extraída, por sua vez, do Banco de Dados Iboruna. Esse corpus, coletado pelo Projeto ALIP (Amostra Linguística do Interior Paulista), representa a variedade falada na região de São José do Rio Preto. Coletado entre março de 2004 e setembro de 2007, constitui o primeiro banco de dados de amostras de fala do interior do Estado de São Paulo, com controle rigoroso dos procedimentos de coleta e dos fatores sociais, abrangendo sete municípios da região noroeste: Bady Bassitt, Cedral, Guapiaçu, Ipiguá, Mirassol, Onda Verde e São José do Rio Preto (GONÇALVES, 2019).

12 Original: “(i) a speaker's choice to place material structurally belonging to an Np outside that Np is determined first and foremost by two independent principles: structural weight and communicative weight; (ii) in the majority of cases these two factors favour the same word order; (iii) where the two factors favour competing word orders, the speaker will try to decide which of the two factors, in the given circumstances and given his/her communicative intentions, outweighs the other in terms of efficiency and effectiveness; (iv) in such situations other (independent) factors may also play a role; these other factors, though usually not strong enough to determine word order by themselves, may therefore tip the balance in the case of a 'draw'; (v) the ultimate order of the elements is the one which the speaker, in the given circumstances, believes to be the most efficient one available or attainable, despite the fact that at least one major word ordering principle has been violated". (KEIZER, 2007, p. 273-274). 
Os informantes, de perfis sociais pré-definidos pelo entrecruzamento das características sociais sexo/gênero, faixa etária, nível de escolaridade e renda familiar, contribuíram com cinco tipos de textos orais diferentes: narrativa de experiência pessoal $(\mathrm{NE})$, narrativa recontada (NR), relato de descrição (DE), relato de procedimento (RP) e relato de opinião (RO). No caso deste trabalho, os diferentes tipos textuais não são em si um critério de análise, mas apenas buscam maior diversidade no domínio do uso da língua falada no contexto social.

Do cruzamento dos grupos de fatores sociais, constituíram-se os perfis da Amostra Censo ou Amostra Comunidade (AC), com a obtenção de um total de 152 informantes. A constituição da amostra de Nps descontínuos requereu o exame dos 152 relatos, um total aproximado de 1,5 milhão de palavras (GONÇALVES, 2019), que forneceram, no final, um total de 334 ocorrências de sintagmas nominais descontínuos, 77 das quais constituindo casos de interrupção e 257, casos de Nps deslocados na oração. Este trabalho se limita à análise, apenas, dos casos de interrupção interna no $\mathrm{Np}$. Como se vê, a frequência de descontinuidade por interrupção é extremamente reduzida em face da grande dimensão da amostra examinada, o que parece ser motivado pela própria natureza do fenômeno, uma vez que se caracteriza justamente pela subversão da ordem de constituintes mais prototípica no português.

No decorrer da análise, as ocorrências são identificadas da seguinte forma: AC001 (corresponde ao número do texto); DE (corresponde ao tipo textual); e L.001 (corresponde à linha em que se localiza a ocorrência).

No levantamento de dados, a estratégia empregada consistiu em verificar se há interferência de elementos na estrutura interna do $\mathrm{Np}$, ou seja, se há o rompimento da contiguidade entre núcleo, determinantes e modificadores pré e pós-nucleares causado pela interrupção de material interveniente. Aplicou-se aos dados da amostra uma quantificação simples que incluiu parâmetros relacionados a traços interpessoais, representacionais e morfossintáticas do $\mathrm{Np}$, conforme os níveis constitutivos da GDF. Para os propósitos deste trabalho, exploram-se os seguintes critérios:

(i) motivação para descontinuidade;

(ii) tipo de material que intervém no $\mathrm{Np}$;

(iii) configuração morfossintática do $\mathrm{Np}$ descontínuo; e

(iv) peso estrutural do elemento deslocado do $\mathrm{Np}$.

\section{Motivações da descontinuidade dos constituintes internos do Np}

Entende-se como descontínuo o $\mathrm{Np}$ que dispõe de constituintes extraídos de seu domínio em virtude de rupturas na linearidade morfossintática. Discutem-se, primeiramente, as motivações para essa descontinuidade, para analisar-se, na sequência, a natureza dos materiais intervenientes que causam a ruptura dos constituintes. 
A Tabela 1 mostra as motivações da descontinuidade dos constituintes do Np, acompanhadas da frequência bruta e do percentual de ocorrências para cada categoria.

Tabela 1 - Motivações da descontinuidade de constituintes do Np.

\begin{tabular}{lcc}
\hline Motivação da descontinuidade & N & $\mathbf{\%}$ \\
\hline Função pragmática Foco & 73 & 94,9 \\
Função pragmática Foco e Complexidade morfossintática & 2 & 2,6 \\
Preservação de relações de escopo & 2 & 2,6 \\
\hline Total & $\mathbf{7 7}$ & \\
\hline
\end{tabular}

Fonte: Souza-Martins (2020b, p. 64).

Em relação ao princípio de foco-final (KEIZER, 2007), um dos principais parâmetros na análise do fenômeno da descontinuidade, a amostra conta com 94,9\% de casos de deslocamento de modificadores do Np para o final da oração em função do estatuto pragmático da informação por eles veiculada. Trata-se, novamente, da atribuição da função pragmática Foco, como se pode verificar em (8-10).

(8) a minha mãe morava em São Pau::lo e ela namorava o::/ um mari/ um:: um rapaz daqui de Rio Preto... eles:.... ela conheceu a partir de uma tia dela que ele chama C. né? o ex-namorado dela... ele morava aqui ele é irmão de um/ do marido da minha tia... então eles namoravam só que assim mais por car::ta por telefone porque como ele morava aqui era mais difícil o conTAto... até que ele começô(u) a fazê(r) escolinha [em São Paulo] da polícia (AC046; NR: L.156)

(9) vamo(s) supor num TEM aquela que ela qué(r)... então você fala assim... ah por exemplo ela ela... ela qué(r) uma saia PREta... e uma blusa... [vamo(s) supor] ROsa... cê num tem a rosa... (AC130; RP: L.371)

(10) Doc.: cê lembra assim de alguns móveis espeCíficos que tinha em cada cômodo? Inf.: lembro Doc.: que que tinha? Inf.: eu lembro:: de todos os móveis mas o que mais me chama atenção é uma copinha [que a minha mãe tinha] de made(i)ra... (AC099; DE: L.317)

É possível perceber que a seleção do Np enfocado em (8) envolve uma competição entre o princípio de complexidade estrutural, contemplando o Nível Morfossintático, e o princípio de foco-final, contemplando o Nível Interpessoal, e que é o que prevalece, já que a oração adjetiva [que a minha mãe tinha] tem um grau maior de complexidade estrutural que o Pp [de madeira]; mesmo assim, o falante abriga o constituinte mais complexo na posição imediatamente pós-nuclear, deixando o item focal na posição final, o que significa dar maior peso a um princípio de ordenação pragmático que a um morfossintático. Outros exemplares similares são as ocorrências em (11-14). 
(11) tem a fabriquinha [que meu pai trabalha lá] de marcenari::a... ele trabalha às vezes (AC025; DE: L.096)

(12) e pegava duas:: mad/ tipo duas made(i)ras né? finas relativamente finas... onde colocava os rolemãs né?... aí na parte de trás... dessa made(i)ra... da ou/ da o(u)tra made(i)ra [que eu tava falan(d)o] plana né?.. (AC049; RP: L.195)

(13) e aí você tendo seu próprio dinhe(i)ro seu próprio sustento... porque é nessa sociedade [em que a gente vive] capitalista... (AC148; RO: L.186)

(14) A. eu gostaria que você me contasse alguma histó::ria [que alGUÉm te contô:: (u)] aLEgre ou triste que você se reCORde (AC001; NR: L.60)

Conforme se vê, todos esses casos violam o Princípio de Complexidade Crescente, já que estruturas mais complexas, como orações relativas, posicionam-se antes das menos complexas, palavras e sintagmas, abrigando-se, desse modo, o elemento focal e mais saliente na posição absoluta $\mathrm{P}^{\mathrm{F}}$. Nesse caso o falante sacrifica o princípio formal de Complexidade Crescente pelo pragmático de Foco-Final.

Em duas outras ocorrências, (15) e (16), os dois princípios favorecem a mesma ordem, já que ambos contribuem para abrigar no final do sintagma o item que contém, ao mesmo tempo, a informação mais nova do discurso e a mais complexa morfossintaticamente.

(15) aí tinha uma prima minha [na ocasião] que fazia Engenharia de Alimentos eu vi com ela mais ou menos como era o curso... (AC083; NE: L.076)

(16) em cima da bancada ficam os equipamen::tos as balan::ças éh:: polaróide:: bom os equipamentos [enfim] que são usados pra pesquisa... e só (AC083; DE: L.225)

Por fim, como última motivação da descontinuidade, detectaram-se 2,6\% de ocorrências em que a ruptura da adjacência dos constituintes ocorre em virtude das relações de escopo entre $\mathrm{Np}$ e modificadores, como se vê em (17) e (18).

(17) eu senti uma responsabilidade tudo nas minhas costa num tinha como... [Doc.: hum ((concordando))] eu senti::... treze ou catorze pessoas [eu num me lembro...] comPLEtamente dependente de mim dentro de um ônibus... e eu num era culpado... (AC109; NE: L.192)

(18) então aí eu peguei... e montei um novo escritório novamente... éh:: alguns clientes [que eu tinha:....] do meu escritório antigo... me deram apo::io vieram pra mim pra que eu pudesse começá(r) novamente... (AC099; NE: L.078) 
Em ambas as ocorrências, os elementos interferentes, no caso, modificadores que escopam apenas o núcleo do $\mathrm{Np}$, rompem com a adjacência dos constituintes. Uma ordenação alternativa que mantivesse essa adjacência poderia comprometer uma interpretação adequada da intenção comunicativa do falante, como se comprova com os exemplos (17') e (18').

(17') treze ou catorze pessoas completamente dependente de mim... eu num me lembro.

(18') alguns clientes do meu escritório antigo que eu tinha.

Em (17'), o posicionamento do modificador [eu num me lembro] no final do sintagma causa ambiguidade no conteúdo da informação sobre o qual o falante manifesta dúvida, não se tratando mais da quantidade de pessoas envolvidas no relato, mas, agora, do Conteúdo Comunicado como um todo.

De modo similar, em (18'), o modificador [que eu tinha] não parece escopar "os clientes", mas o "escritório antigo", produzindo ambiguidade na interpretação do enunciado. Consequentemente, abrigar esses elementos na posição imediatamente pós-nuclear parece ser a decisão mais adequada ao falante para que a mensagem não seja mal interpretada pelo interlocutor.

Tendo discutido as motivações que subjazem à descontinuidade do $\mathrm{Np}$, fazse necessário, também, descrever a natureza dos elementos que podem interferir na adjacência de seus constituintes. Esse material interveniente recebeu a seguinte classificação:

(i) modificador sintagmático;

(ii) modificador oracional (oração); e

(iii) operador.

A tabela 2 mostra os diferentes elementos que podem intervir na ordenação dos constituintes do $\mathrm{Np}$ e o número de ocorrências para cada tipo.

Tabela 2 - Tipos de elementos intervenientes no Np.

\begin{tabular}{llc}
\hline Tipo de elemento interveniente & N & $\mathbf{\%}$ \\
\hline Modificador oracional & 31 & 40,3 \\
Modificador sintagmático & 30 & 39 \\
Operador & 16 & 20,8 \\
\hline Total & $\mathbf{7 7}$ & \\
\hline
\end{tabular}

Fonte: Adaptado de Souza-Martins (2020b, p. 67). 
Em primeiro lugar, modificadores sintagmáticos de diferentes níveis e camadas podem ser responsáveis pela interrupção dos constituintes do $\mathrm{Np}$, o que se aplica a $39 \%$ das ocorrências. Classificam-se como modificador de Subato de Referência (19), que é uma camada do Nível Interpessoal, e modificador de Estado de Coisas (20a-c), que são modificadores do Nível Representacional.

(19) então eu acho que é até explicável o fato de... os docentes [por exemplo] de uma universidade pública não terem essa iniciativa... pra... interferí(r) no ensino... fora da universidade... no ensino básico... (AC082; RO: L.439)

(20) a. fui entran(d)o na sociedade assim... eles gostava muito de mim era muito de confiança... eu ia na Redentora lavava o carro [lá na Redentora] do pessoal tudo eles me considerava muito... eu trabalhei pa muito juiz tam(b) ém (AC097; NE: L.031)

b. Selma também foi uma pessoa interessante na história de Rio Preto... éh:: a vinda [em trinta e oito...] do:: ((barulho de carros)) Getúlio Vargas... presidente... presidente entre aspas... [Doc.: ((risos))] né?... éh:: da República... (AC146; NE: L.057)

c. "olha se eu dé(r) uma:: dosagem normal [pra ele...] de de antibiótico num vai resolvê(r)... amanhã esse menino tá morto... de uma mane(i)ra ou de o(u)tra... agora:: se a gente aumentá(r) isso... se eu dé(r) uma uma dosagem dupla pra ele talvez ele:: sobreviva... se o senhor autorizá(r)"(AC143; NR: L.138)

Em (19), o modificador de Subato de Referência indicando exemplificação deveria, idealmente, alojar-se nos limites do sintagma que ele restringe, conforme entende Pezatti (2014). No entanto, tendo um estatuto pragmático focal, o Pp [de uma universidade pública] se abriga em $\mathrm{P}^{\mathrm{F}}$ do $\mathrm{Np}$, o que leva o modificador de exemplificação para a posição relativa $\mathrm{P}^{\mathrm{F}-1}$. O mesmo se aplica aos modificadores de Estado de Coisas em (20a-c), que mantêm preferência pelo domínio de $\mathrm{P}^{\mathrm{F}}$.

Quando houver, o deslocamento se processa, na realidade, em relação à posição canônica que os constituintes ocupariam, caso não houvesse a decisão do falante de salientar a informação veiculada apenas em uma parte do Np todo, o que é, de fato, a motivação para a ordenação final dos constituintes.

Outras ocorrências reposicionam os modificadores do núcleo do Np, como se vê nos exemplos (21a-b), tornando-se impreciso, nesses casos, determinar se o fenômeno é interrupção. A decisão metodológica mais adequada para as motivações para esse reposicionamento parece ser a mesma que se tomou para os casos de interrupção, ou seja, enquadrá-los, para fins de análise, na categoria "interrupção por modificadores". 
(21) a. Doc.: éh eu gostaria então agora de sabê(r) qual que é sua opinião a respeito do do do time [do São Paulo] novo o novo time que o... técnico montô::(u)... se ele vai dá(r) certo no campeona::to que que você acha? (AC095; RO: L.107)

b. sei que elas inventaram a maior sopa... e conversan(d)o conversan(d)o os maridos chegaram começaram a tomá(r) uísque... e conversando tal e a sopa foi cozinhando e essa irmã [ da minha mãe] mais velha ela sempre contava (AC148; NR: L.084)

Casos como (21a) afetam as relações de escopo dos modificadores do núcleo, uma vez que novo, que tem time em seu escopo, ao inserir-se após o aposto, provoca uma situação de ambiguidade em virtude do fato de que, ao ser realocado, parece ter seu escopo incidindo agora sobre o Pp [do São Paulo].

Vale ressaltar que o adjetivo novo aqui enfocado, sinônimo de recente, consiste num modificador dêitico de tempo; como sua inserção se dá no Nível Interpessoal, o português dispõe de uma ordem especial para ele, que é na posição pré-nuclear; se alocado na posição pós-nuclear, tem um valor representacional e diz respeito à idade do referente (NHOATO, 2018).

No caso específico de (19a), é possível afirmar que, ao perceber a ambiguidade ativada pela descontinuidade, o falante reformula seu discurso para o novo time que o técnico montou, em atenção às relações de escopo e de ordenação. A consequência é não apenas inserir o modificador na posição adjacente ao núcleo, mas também na pré-nuclear, o que implica restabelecer os valores tipicamente pragmáticos envolvidos nessa codificação morfossintática.

Similarmente, também se manifesta um valor de ambiguidade, em (19b), pelo reposicionamento do modificador [mais velha] para o fim do sintagma, que agora parece escopar o Pp [da minha mãe]. Diferentemente de (19a), o que se tem aqui é uma ambiguidade em relação ao valor semântico de velho, antônimo de novo, já que se limita ao conteúdo tipicamente representacional de idade, não interpessoal de tempo. Nesse caso, contudo, o que é equivocada é a interpretação [a minha mãe mais velha], porque o Destinatário, fazendo uso de seu conhecimento de mundo, não desconhece a impossibilidade de haver alguém que tenha, pelo menos do ponto de vista biológico, duas ou mais relações de parentesco materno. ${ }^{13}$ Em consequência disso, sua opção cognitiva se volta para a interpretação mais apropriada, que é a que, apesar da descontinuidade, entende o sintagma [mais velha] como modificador apenas do núcleo [essa irmã].

Em segundo lugar, em 40,3\% dos casos, o elemento que causa a interrupção no Np é uma oração relativa (22a-b) ou uma oração adverbial (23a-b).

13 Não se pode descartar, todavia, a situação possível de um casal de mulheres lésbicas, uma mais velha que a outra, ter adotado uma criança que, já em fase adulta, poderia referir-se a uma delas como "minha mãe mais velha". 
(22) a. e é a parte [que eu mais fico] da casa é no meu quarto [Doc.: sei] porque até assistí(r) televisão ma/ eu mai/ eu assisto mais no meu quarto do que na sala a sala eu de(i)xo po/ pos menino... (AC110; DE: L.239)

b. sabe aquelas po(I)pas [que cê compra] de maracujá... [Doc.: sei] tem de todos... sabor... [Doc.: sei] no mercado... então a polpa da Bras/ Brasfrut... [Doc.: ah sei] tem de maracujá... cê... bate [(uma/)] Doc.: [é melhor] que fica mais firminho? Inf.: fica mais firme... (AC090; RP: L.389)

(23) a. AH agora eu lembrei... eu tinha uma mania [quando era pequena] de colocá(r) as coisa na gelade::(i)ra.... -- o meu pai -- ((o pai passa de moto na frente de onde estávamos gravando a entrevista)) é:: eu tinha mania d/ mania de colocá(r) as coisa na gelade(i)ra... JÁ coloquei hominho do meu irmão (AC006; NR: L.200)

b. HÁ cinco departamentos há vários departamentos mas... o prédio principal... é o E um o prédio principal... havia antes pra inauguração o projeto pra tê(r) dois prédios de oito andares [se eu num me engano...] de vidro... mas um SÓ tem hoje né (AC081; DE: L.120)

É relevante afirmar que, embora essas orações também atuem como modificadores do $\mathrm{Np}$, criou-se uma categoria à parte em virtude da diferença de complexidade entre modificadores sintagmáticos e modificadores oracionais. Assim, a análise desse tipo de ocorrência aponta para a violação do princípio morfossintático de complexidade crescente, pois, embora modificadores sintagmáticos sejam menos complexos que os oracionais, há uma preferência por alocá-los na posição final do $\mathrm{Np}$, por conta de seu estatuto pragmático, mesmo que essa preferência produza sintagmas descontínuos e com alto grau de ambiguidade, como se observa em (24) e (25).

(24) Doc.: A. eu gostaria que você me contasse alguma histó::ria [que alGUÉm te contô:: (u)] aLEgre ou triste que você se reCORde (AC001; NR: L.60)

(25) Doc.: seu pai era o pior deles? Inf.: meu pai... PElo que FAlam e depois fui crescen(d)o e ven(d)o os outros tio... tem:: ti::os né? [uns que já faleceram] de gênio forte mas acredito que o do meu pai é... foi o pior (AC110; NR: L.171)

É nítido que o deslocamento dos modificadores [alegre ou triste] e [de gênio forte] para o fim do sintagma causa certa imprecisão semântica a respeito do caráter denotativo do elemento sobre o qual incide de fato o escopo deles, abrindo espaço para interpretações equivocadas como o modo que alguém contou a história, em (24), e a causa do falecimento dos tios, em (25). Essa ambiguidade seria resolvida com a linearização desses modificadores logo após a posição pós-nuclear do $\mathrm{Np}$, o que também atenderia ao Princípio de Complexidade Crescente. Contudo, apesar de 
produzir descontinuidade, a escolha do falante, no momento da interação, é a que ele julga mais eficiente para realizar seus propósitos comunicativos.

Em último lugar, detectamos também operadores de diferentes camadas interferindo nos constituintes do Np, equivalendo a 20,8\% das ocorrências: operador de Subato de Atribuição (26); operador de Subato de Referência (27); operador de Contraste (28); e operador argumentativo (29).

(26) ele contô(u) que ele tava na::... numa casa lá tinha mu/ eu num lembro num sítio... lá no Ceará tam(b)ém... aí de repente parô(u) um caminhão:: na estrAda... um estradão $[$ assim] de TErra... pa pedí(r) informação né?... (AC054; NR: L.133)

(27) vamo(s) lê(r)... num tenho muita leitura não... mas eu leio a bíblia tam(b)ém... leio... gosto muito de í(r) na igreja... traba::lho também assim... na igreja... na parte $[$ assim...] dos pobre (AC122; RO: L.474)

(28) e tem o éh::... éh:: uma quadra pra jogá::(r) basque::te vô::lei e tem a quadra [tam(b)ém] de futebol... (AC030; DE: L.090)

(29) em cima da bancada ficam os equipamen::tos as balan::ças éh:: polaróide:: bom os equipamentos [enfim] que são usados pra pesquisa... e só (AC083; DE: L.225)

Além das motivações já discutidas, o operador assim interrompe o fluxo do Np para indicar mitigação em (26) e (27). Esse fator não determina a ordenação dos elementos das duas construções, mas pode interferir na opção do falante pela ordem mais adequada da construção em cumprimento de seu objetivo comunicativo. Uma vez que buscam causar esse efeito de mitigação em apenas uma parte do $\mathrm{Np}$ (isto é, no modificador), esse tipo de operador se abriga sempre antes do elemento escopado (PEZATTI, 2014), o que também justifica a posição que ocupa em (26) e (27).

As duas outras ocorrências contêm palavras gramaticais simples, como também e enfim, atuando como operadores. Em (28), o operador de contraste expansivo, codificado por também, "indica que o Destinatário dispõe de uma informação parcial que necessita ser completada” (PEZATTI, 2014, p. 109). Já o operador enfim de (29) parece fechar um argumento do Emissor.

Da correlação entre os resultados da Tabela 1 (motivações da descontinuidade) e da Tabela 2 (tipos de materiais intervenientes), constata-se que, independentemente do tipo de material interveniente, é sobre a função focal que incide a maior parte das interrupções no Np, o que representa 93,5\% (29/31) das ocorrências de interrupção por modificador oracional; $96,6 \%$ (29/30) das ocorrências de interrupção por modificador sintagmático; e 93,7\% (15/16) das ocorrências de interrupção por operador. 
Examinando-se agora os resultados referentes à configuração morfossintática do $\mathrm{Np}$, a Tabela 3 mostra cada tipo acompanhado da respectiva incidência quantitativa na amostra.

Tabela 3 - Configuração morfossintática do Np descontínuo.

\begin{tabular}{lcc}
\hline Padrão de configuração morfossintática & N & \% \\
\hline Determinante + núcleo + material interveniente + modificador & 74 & 96,1 \\
Determinante + modificador + material interveniente + núcleo & 1 & 1,3 \\
Determinante + núcleo + modificador + material interveniente + modificador & 2 & 2,6 \\
\hline Total & $\mathbf{7 7}$ & \\
\hline
\end{tabular}

Fonte: Souza-Martins (2020b, p.73).

A maior parte dos casos, um índice de $96,1 \%$ das ocorrências, apresenta o padrão [determinante + núcleo + material interveniente + modificador], o que permite considerar que a descontinuidade prototípica é motivada pela interferência de material interveniente entre o núcleo e o modificador pós-nuclear, em vista da incidência majoritária deste na função focal (como já visto na Tabela 1), que, por sua vez, se caracteriza por abrigar-se mais na posição final da expressão linguística.

Outros padrões de organização morfossintática foram encontrados na amostra, mas, como é possível perceber na Tabela 3, seus índices de ocorrência são extremamente reduzidos e pouco significativos se comparados com os do molde (template) prototípico.

Além dessa configuração morfossintática prototípica, os dados apontam para interferências entre modificadores do núcleo do $\mathrm{Np}(30)$ e entre modificador pré-nuclear e núcleo (31).

(30) então eu acho que deveria tê(r)... uma faculdade? NÃO... mas um curso... BÁ::sico [sei lá] de administração... certo?... e a pessoa teria que tê(r) um mínimo de estudo pra podê::(r)... sê(r)... um... um político (AC075; RO: L.293)

(31) Doc.: assim eu sei que você faz balé... tem como você falá(r) como você faz determinados... [não sei se é esse o termo]... passos tem como você falá(r)? (AC018; RP: L.120)

O baixo índice de interferência entre modificadores pré-nucleares e núcleo em contraste com o grande número de casos em que há interrupção entre núcleo e pósmodificadores é uma constatação que está em conformidade com o que postula Van de Velde (2012, p. 14, tradução nossa): "modificadores pós-nucleares - mesmo se eles se qualificam como complementos e não como adjuntos - estabelecem uma relação mais frouxa com o $\mathrm{Np}$ do que os modificadores pré-nucleares (incluindo os 
determinantes)". ${ }^{14}$ Essa configuração licenciaria mais facilmente a distância linear entre núcleo e modificadores pós-nucleares causada pela intervenção de diferentes elementos.

É válido considerar, contudo, que a constatação de Van de Velde (2012) se aplica à gramática do holandês. No caso do português em geral, a posição pré-nuclear é reservada para modificadores que atuam no Nível Interpessoal (NHOATO, 2018). Sendo assim, pode-se concluir que a interferência de elementos nos constituintes do Np é rara na porção pré-nuclear, uma vez que ela fica reservada a um conjunto de modificadores com reduzida frequência. Como é na posição pós-nuclear que se aplica mais frequentemente uma grande variedade semântica de modificadores, ela acaba por constituir o espaço privilegiado para a descontinuidade.

Avançando agora para outro critério morfossintático, o que se refere ao peso estrutural do modificador extraído do domínio do $\mathrm{Np}$, na grande parte das ocorrências, trata-se de um sintagma preposicional $(\mathrm{Pp})$, conforme ilustram os resultados contidos na Tabela 4.

Tabela 4 - Peso estrutural do modificador deslocado.

\begin{tabular}{lcc}
\hline Configuração morfossintática do modificador deslocado & N & \% \\
\hline Sintagma preposicional (Pp) & 54 & 72 \\
Adjetivo simples & 17 & 22,7 \\
Oração relativa, adverbial ou outro tipo de relação com verbo não-finito & 4 & 5,3 \\
Total & $\mathbf{7 5}^{15}$ & \\
\hline
\end{tabular}

Fonte: Adaptado de Souza-Martins (2020b, p.75).

Reforçando a análise de Van de Velde (2012), os dados da tabela 4 permitem afirmar que o Pp é o modificador que mais tende a desmembrar-se do núcleo do $\mathrm{Np}$, o que se justificaria, uma vez mais, pelo fato de ser uma relação que se estabelece entre núcleo e modificador no Nível Representacional. Em função desse elo, o Destinatário é capaz de estabelecer as relações semânticas necessárias para a interpretação da mensagem, ainda que haja descontinuidade e distanciamento desses constituintes na codificação linear do Nível Morfossintático. No caso da variedade examinada, esse sintagma preposicional é introduzido, na grande maioria dos casos, pela preposição $d e$, talvez por conta da multifuncionalidade e da alta frequência de uso desse operador no português.

\footnotetext{
14 Original: "postmodifiers - even if they qualify as complements rather than as adjuncts - are argued to stand in a more loose relationship to the NP than premodifiers (including the determiners)." (VAN DE VELDE, 2012, p. 14).

15 Excluem-se os casos em que a interferência se dá entre modificador pré-nuclear e núcleo.
} 


\section{Palavras finais}

A análise dos Nps descontínuos aqui proposta partiu de uma hipótese central, fundamentada numa teoria multifuncional, inicialmente postulada por Dik (1997) e depois incorporada por Keizer (2007). Dois parâmetros cruciais estão em jogo: o peso estrutural, morfossintaticamente motivado, e o peso comunicativo, pragmaticamente motivado.

Se, em geral, como diz Keizer (2007), no fenômeno da descontinuidade interna do $\mathrm{Np}$, esses dois parâmetros podem favorecer juntos a mesma ordenação ou competir entre eles, caso em que cabe ao falante decidir que parâmetro supera o outro em termos de eficiência comunicativa nas circunstâncias discursivas, o que ocorreu, na verdade, foi a atuação mais predominante do princípio de foco-final, determinando, sozinho, a ordenação final dos elementos constituintes do $\mathrm{Np}$.

O princípio de complexidade é, por outro lado, uma motivação só aparentemente morfossintática, já que sua força é garantir uma ordenação cognitivamente aceitável para os constituintes do $\mathrm{Np}$, deixando para as posições finais as unidades formais mais complexas, o que alivia o peso do processamento cognitivo tanto do ponto de vista do emissor quanto do ponto de vista do destinatário.

Do ponto de vista morfossintático, predomina nos dados analisados um padrão de organização formal, que também pode ser considerada prototípica do Np descontínuo, contemplando a emergência de material interveniente entre o núcleo do $\mathrm{Np}$ e seu modificador pós-nuclear, que, na maioria dos casos, tende a ser um Pp, certamente motivado pelo seu estatuto interpessoal de foco. Esse tipo de configuração aponta para o que Van de Velde (2012) chama de relacionamento "mais frouxo" entre núcleo e modificador pós-nuclear, espaço privilegiado para a intervenção de elementos e o consequente deslocamento do Pp para a parte final do sintagma.

Uma questão relevante a levantar é: como garantir, em caso de descontinuidade, um grau mínimo de interpretabilidade e conexão semântica entre as partes do Np? A resposta está no fato de que o fenômeno da descontinuidade corresponde a uma circunstância específica em que entidades relacionadas pragmática e semanticamente são codificadas separadamente no Nível Morfossintático. Nesse caso, elementos morfossintáticos não adjacentes não podem formar um único constituinte numa interpretação funcional, mas podem ter uma projeção representacional cujo valor semântico garanta a formação de uma unidade (HUCK; OJEDA, 1987 apud GARCÍA VELASCO, 2010).

O modelo teórico da GDF, organizado em níveis e camadas, permite mostrar que, embora separados no Nível Morfossintático, núcleo e modificador pós-nuclear mantêm uma relação coesiva no Nível Representacional. Observe-se, no Np em (32), o modo como a GDF permite representar o fenômeno da descontinuidade, mostrado em (33).

(32) e a sopa foi cozinhando e essa irmã [da minha mãe] mais velha ela sempre contava (AC148; NR: L.084) 
(33) Essa irmã da minha mãe mais velha

NI: $\left(\mathrm{R}_{\mathrm{I}}:\left[\left(\mathrm{T}_{\mathrm{I}}\right)\left(\mathrm{T}_{\mathrm{J}}\right)\left(\mathrm{T}_{\mathrm{K}}\right)_{\mathrm{FOC}}\right]\left(\mathrm{R}_{\mathrm{I}}\right)\right)$

NR: $\left(\mathrm{x}_{\mathrm{i}}\right.$ : essa irmã $\left[\left(\right.\right.$ mais velha $\left._{\mathrm{Mod}}\right)$ (da minha mãe $\left.\left.\left.{ }_{\text {Mod }}\right)\right]\left(\mathrm{x}_{\mathrm{i}}\right)\right)$

NM: $\left(\mathrm{Np}_{\mathrm{i}}\right.$ : essa irmã $\left(\mathrm{Np}_{\mathrm{i}}\right)\left[\left(\mathrm{Pp}_{\mathrm{i}}:\left(\mathrm{Pp}_{\mathrm{i}}\right.\right.\right.$ : da minha mãe $\left.\left(\mathrm{Pp}_{\mathrm{i}}\right)\right)\left(\mathrm{Ap}_{\mathrm{i}}\right.$ : mais velha $\left.\left.\left(\mathrm{Ap}_{\mathrm{j}}\right)\right]\left(\mathrm{Np}_{\mathrm{i}}\right)\right)$

A notação formal indica que, no Nível Interpessoal (NI), um Subato referencial [essa irmã da minha mãe mais velha] contém três Subatos atributivos, um dos quais é o focal [mais velha]. No Nível Representacional (NR), esse Subato referencial corresponde a uma entidade de primeira ordem ou um Indivíduo (x) especificado por dois modificadores, cuja designação lhe garante unidade denotativa. Já no Nível Morfossintático, essa entidade referencial e denotativa é representada por três categorias formais: um sintagma (Np), um sintagma adjetival (Ap) e um sintagma preposicional (Pp); é nesse nível de codificação que se formaliza a descontinuidade, que, como uma ruptura na ordem linear da oração, é um fenômeno tipicamente morfossintático.

Para finalizar, é possível concluir que uma arquitetura modular, como a da GDF, viabiliza uma interpretação da descontinuidade que permite, por um lado, separar constituintes, como núcleo e modificador pós-nuclear, no Nível Morfossintático e, por outro, conectá-los semanticamente no Nível Representacional. O que provoca essa incompatibilidade entre os níveis é claramente a violação de princípios regulares, especialmente o de Estabilidade Funcional, cujo efeito mais geral é, portanto, falta de transparência linguística no que diz respeito à correspondência entre os níveis Representacional e Morfossintático.

É responsabilidade do falante favorecer uma ordem final na qual deposita a crença de que, nas circunstâncias discursivas em que encontra seu destinatário, é a ordem selecionada a mais eficiente entre as disponíveis, não importa se tiver violado pelo menos um princípio crucial de ordenação, como o de iconicidade, o de estabilidade funcional e o de integridade de domínio.

O discurso em si, na realidade, viola constantemente esses três princípios, que exercem seu papel na língua mais como a força centrípeta de manter, na codificação, uma ordenação de formas que estejam necessariamente alinhadas com as categorias exercendo funções nos níveis mais altos de formulação. Ao violar esses três princípios, o discurso mostra uma força notadamente centrífuga, que é, numa comparação quantitativa intuitiva, menos frequente que as motivações que atuam como força centrípeta. A grande maioria dos Nps tem ordem canônica, não sendo, portanto, marcada por ruptura de ordem, em obsequioso respeito do falante aos princípios mais gerais da gramática. 
CAMACHO, R. G.; SOUZA-MARTINS, N. P. de. Discontinuous Noun Phrases. Alfa, São Paulo, v.65, 2021.

- ABSTRACT: The phenomenon this paper focuses on is the noun phrase (Np) that presents non-canonical order of its constituent parts, called "discontinuous" by Keizer (2007). The analysis and description of discontinuity aims to examine which pragmatic, semantic and formal factors motivate the speaker's choice to encode specific orderings to these Nps at the Morphosyntactic Level based on the theoretical framework of Functional Discourse Grammar (HENGEVELD; MACKENZIE, 2008). The sample is constituted from spoken language records from the Iboruna database, which represents the spoken variety in the northwest of São Paulo State, collected by the ALIP project, within the Functional Grammar Research Group, at UNESP, in São José do Rio Preto. For the purposes of this work, the following criteria are explored: (i) motivation for discontinuity; (ii) type of intervening material in the $\mathrm{Np}$; (iii) morphosyntactic configuration of the discontinuous $\mathrm{Np}$; and (iv) structural weight of the element displaced from the Np. The analysis shows that discontinuity is predominantly motivated by pragmatic aspects, in particular, by the focal status of information provided by part of the $\mathrm{Np}$. Furthermore, the prototypical discontinuous $\mathrm{Np}$ is characterized by the interference of morphosyntactic material between the head noun and its postnuclear constituents. Although there is this linear distancing, the comprehension of discontinuous statements is not impaired due to a semantic link preserved at the Representational Level, a possible interpretation in a theoretical model such as FDG.

- KEYWORDS: noun phrase; discontinuity; focus.

\section{REFERÊNCIAS}

CAMACHO, R. G. Motivações discursivas para a descontinuidade morfossintática do SN. Odisséia, Natal, RN, v. 2, n. esp., p. 58-79, 2017.

DIK, S. C. The Theory of Functional Grammar. Edited by Kees Hengeveld. Berlin: New York: Mouton de Gruyter, 1997. Part I: the structure of the clause. (Functional Grammar, 20).

DU BOIS, J. W. Competing motivations. In: HAIMAN, J. (ed.). Iconicity in syntax. Amsterdam: Philadelphia: John Benjamins, 1985. p. 343-365.

GARCÍA VELASCO, D. Discontinuity and Displacement in a Functional Theory of Grammar. In: INTERNATIONAL AEDEAN CONFERENCE ALMERIA, 34., Oviedo. Proceedings [...], Oviedo: University of Oviedo, 2010. p. 412-420.

GONÇALVES, S. C. L. Projeto ALIP (Amostra Linguística do Interior Paulista) e banco de dados Iboruna: 10 anos de contribuição com a descrição do português brasileiro. Revista Estudos Linguísticos. São Paulo, v. 48, n. 1, p. 276-297, 2019. 
HAWKINS, J. A. Word order universals. New York: Academic Press, 1983.

HENGEVELD, K. Transparency in Functional Discourse Grammar. Linguistics in Amsterdam, Amsterdam, v.4, n.2, p. 1-22, 2011.

HENGEVELD, K. Prototypical and non-prototypical noun phrases in Functional Discourse Grammar. In: RIJKHOFF, J.; GARCÍA VELASCO, D. (ed.). The Noun Phrase in Functional Discourse Grammar. Mouton de Gruyter: Berlin, 2008. p. 221-261.

HENGEVELD, K.; MACKENZIE, J. L. Gramática Discursivo-Funcional. In: SOUZA, E. R. (org.). Funcionalismo linguístico: novas tendências teóricas. Tradução por Marize Mattos Dall'Aglio-Hattnher. São Paulo: Contexto, 2012. p 43-86.

HENGEVELD, K.; MACKENZIE, J. L. Functional Discourse Grammar: a typologically-based theory of language structure. Oxford: Oxford University Press, 2008.

KEIZER, E. The English Noun Phrase. Cambridge: Cambridge University Press, 2007.

LEUFKENS, S. The transparency in language: a typological study. 2015. 197p. Thesis (Doctorate in Linguistics) - Universiteit van Amsterdam, Amsterdam, 2015.

MALLINSON, G-B.; BLAKE, J. Language typology: cross-linguistic studies in syntax. Amsterdam: NorthHolland, 1981.

NEVES, M. H. M. As estratégias discursivas e suas implicações na relação entre oralidade e escrita: um estudo do parêntese na crônica. Linguística, Montevideo, v. 27, p.77-97, 2012.

NHOATO, H. Propriedades semânticas e pragmáticas de modificadores do núcleo do sintagma nominal. 2018. 145f. Dissertation (Masters in Linguistics) - Instituto de Biociências, Letras e Ciências Exatas, Universidade Estadual Paulista, São José do Rio Preto, 2018.

PERINI, M. A. Gramática Descritiva do português. São Paulo: Ática, 1995.

PEZATTI, E. G. A ordem das palavras no português. São Paulo: Parábola, 2014.

SOUZA-MARTINS, N. P. de. O sintagma nominal descontínuo: ordenações não canônicas dos constituintes do SN no português do interior paulista. Revista Estudos Linguísticos, São Paulo, v. 49, n. 1, p. 312-326, 2020 a.

SOUZA-MARTINS, N. P. de. Motivações funcionais da descontinuidade sintagmática. 2020. 94f. Dissertação (Mestrado em Linguística) - Instituto de Biociências, Letras e Ciências Exatas, Universidade Estadual Paulista, São José do Rio Preto, 2020b.

VAN DE VELDE, F. Pp extraction and extraposition in Functional Discourse Grammar Language Sciences, Tokyo, v. 34, p. 433-454, 2012. 
Recebido em 4 de fevereiro de 2020

Aprovado em 10 de agosto de 2020 